\title{
LOS PUEBLOS INDÍGENAS DE IBEROAMÉRICA ANTE LA CRISIS DE 1808
}

\author{
Federico Navarrete \\ Instituto de Investigaciones Históricas - UNAM
}

\section{Resumen}

Este artículo presenta un panorama comparativo de la situación de las sociedades indígenas americanas en 1808 alrededor de tres líneas de análisis centrales: su grado de autonomía ecológica, su capacidad de control cultural y su capacidad de etnogénesis. La comparación se extiende más allá de las sociedades sedentarias y estratificadas de Mesoamérica y los Andes para incluir a los grupos no estatales de las tierras bajas de América del Sur y del norte de Nueva España y sirve de base para comprender sus reacciones contrastantes a la crisis de los imperios ibéricos iniciada en ese año.

\section{Pallabras claves}

Colonialismo • identidad cultural • etnicidad $\bullet$ resistencia $\bullet$ ecología humana.

\section{Abstract}

This article presents a comparative overview of the situation of the Indigenous societies of the Americas in 1808 around three main lines of analysis: their degree of ecological autonomy, their capacity for cultural control, and their capacity for ethnogenesis. The comparison extends beyond the sedentary, stratified societies of Mesoamérica and the Andes to include non-State groups in Lowland South America and Northern New Spain, and tries to explain their contrasting reactions to the crisis of the Iberian empires that started that year.

\section{Keywords}

Colonialism $\bullet$ cultural identity $\bullet$ ethnicity $\bullet$ resistance $\bullet$ human ecology.

\footnotetext{
${ }^{1}$ Agradezco la lectura y comentarios de Ethelia Ruiz Medrano.
} 
Como todos los otros grupos humanos que integraban las sociedades iberoamericanas, los pueblos amerindios fueron profundamente afectados por la crisis de las monarquías ibéricas que se inició en 1808 y que llevaría, en menos de dos décadas, a la disolución de los imperios español y portugués en nuestro continente. Estos pueblos constituían la mayoría de la población de América en ese momento y dominaban la mayor parte de su territorio. Sin embargo, su situación en los albores de esta gran transformación histórica y su participación en los eventos que se desencadenaron a partir de 1808 ha sido poco estudiada y poco discutida por los historiadores. Sabemos mucho más de la situación, formas de pensar y las acciones de otros grupos, como los descendientes de europeos nacidos en América e, incluso, de los esclavos africanos y afroamericanos. ${ }^{2}$

Para comenzar a subsanar este vacío, el presente artículo presentará un panorama comparativo de la situación de las sociedades indígenas a principios del siglo XIX en algunas regiones claves del imperio español y del imperio portugués. No se presentará una visión exhaustiva ni detallada, tanto por falta de espacio como por falta de elementos para poder hacerlo: no sólo porque sería imposible para un solo investigador manejar la totalidad de la literatura sobre el tema, sino también porque ésta no cubre a todas las sociedades amerindias en todas las regiones. Las lagunas en nuestros conocimientos son particularmente graves en lo que se refiere a la situación de las sociedades de agricultores aldeanos y de cazadores y recolectores que todavía no habían sido dominadas por los imperios ibéricos en América del Norte, Central y del Sur y por ello, nuestra visión de ellas será aún más somera y general que las de las sociedades de agricultores estatales de los Andes y Mesoamérica. ${ }^{3}$

Para plantear este panorama comparativo de la situación de sociedades y realidades culturales y políticas tan diferentes en las diversas colonias iberoamericanas se definirán las siguientes tres variables claves:

a) el grado de autonomía ecológica del que disfrutaban, es decir, la medida en que todavía controlaban sus formas de producción y de reproducción física y social en estrecha relación con su medio ambiente;

\footnotetext{
${ }^{2}$ Respecto a estos grupos véase el excelente estudio panorámico de ANDREWS, George Reid. Afro-Latin America 1800-2000. Nova York: Oxford University Press, 2004.

${ }^{3}$ Otro propósito de este artículo es presentar una guía bibliográfica actualizada sobre las sociedades indígenas a fines del periodo colonial. Una bibliografía mas amplia se puede consultar en el sitio web del Proyecto de Investigación "Hacia otra historia de América: la visión de los indígenas" de la Universidad Nacional Autónoma de México, en http://america.historicas.unam.mx.
} 
b) El grado de control cultural que ejercían, es decir, hasta qué punto eran capaces de controlar y dirigir las dinámicas de cambio cultural en que participaban, tanto las que les eran impuestas por los poderes coloniales como las que eran producto de sus propias dinámicas internas de transformación sociocultural;

c) Su capacidad de etnogénesis, es decir, la posibilidad efectiva que tenían de defender y modificar sus identidades étnicas para poder actuar en la sociedad más amplia y defender sus intereses; así como su capacidad para retomar y aprovechar las prácticas e ideas políticas novedosas introducidas por otros grupos sociales y crear alianzas y coaliciones eficaces con ellos.

El análisis de estas variables en diferentes sociedades amerindias nos permitirá comprender mejor la manera tan disímola en que reaccionaron a la crisis de 1808 y las diferentes capacidades que tuvieron para participar en los trastornos subsecuentes.

\section{La situación colonial}

Para el siglo XIX, casi todas las sociedades indígenas en Iberoamérica habían sido profundamente afectadas por su relación con las sociedades coloniales establecidas por españoles y portugueses. El hecho mismo de que usemos el término "indios" para referirnos a todos los pueblos que habitaban originalmente en el continente americano y a sus descendientes es ya producto de esta situación colonial. Como ha señalado Guillermo Bonfil, la categoría de indio fue un instrumento de dominación colonial que agrupó a estos disímbolos grupos humanos y los colocó en una posición de inferioridad respecto a los europeos que justificaba su conquista y sumisión política, así como el despojo de sus tierras y otros recursos naturales, y la explotación forzosa de su mano de obra. ${ }^{4}$

La categoría de indio, y las otras categorías étnicas, como español o portugués, criollo, mestizo, negro y mulato, entre otras, integraron a las sociedades indígenas en un sistema jerárquico basado en la diferenciación y segregación de los grupos humanos definidos como diferentes por sus orígenes y su situación social. ${ }^{5}$ En el caso de São Paulo en Brasil, la palabra indio se usaba para refe-

\footnotetext{
${ }^{4}$ BONFIL BATALLA, Guillermo. El concepto de indio en América: una categoría de la situación colonial. In: Obras escogidas de Guillermo Bonfil. México: Instituto Nacional Indigenista-Instituto Nacional de Antropología e Historia, 1995, vol. 1, p. 337-345.

${ }^{5}$ Los criterios de diferenciación eran complejos, pues incluían elementos culturales y "biológicos",
} 
rirse a los indígenas ya sometidos, y esclavizados, mientras que los miembros de sociedades libres eran conocidos como "negros da terra". ${ }^{6}$

El catolicismo era central para el funcionamiento y la legitimación de los dos imperios ibéricos. Su carácter profundamente religioso les daba una vocación universalista que los impulsaba a someter e integrar a todos los indígenas. ${ }^{7}$ Por ello la Iglesia católica y sus múltiples órdenes jugaron papeles protagónicos y muy complejos en el sometimiento y gobierno de los distintos pueblos amerindios.

Más allá de estos elementos comunes, los gobiernos coloniales reconocieron la existencia de diferentes tipos de sociedades indígenas y concibieron distintas maneras de dominarlos y aprovechar sus tierras y su trabajo.

Tras su rápido sometimiento militar, los pueblos de agricultores estatales de Mesoamérica y los Andes fueron considerados vasallos del rey de España y se construyó el marco legal de las "repúblicas de indios" para definir sus derechos y obligaciones, entre las que se contó el pago de tributo y el trabajo forzoso, bajo la forma de instituciones como la encomienda, el repartimiento y la mita. ${ }^{8}$ Estas instituciones se basaron en buena medida en las formas de exacción de tributo y trabajo que habían desarrollado los estados indígenas prehispánicos. Esto significó también, al menos en principio, el reconocimiento de la propiedad de las comunidades campesinas sobre sus tierras, pues la Corona española descubrió rápidamente que la única manera de garantizar su supervivencia, y su continuada explotación, era permitirles un cierto grado de autonomía ecológica.

La diversidad original de estas sociedades, las distintas circunstancias en que fueron conquistadas y la evolución divergente de los regímenes coloniales marcaron profundas diferencias en la aplicación de este marco general entre las colonias españolas: mientras que en el centro de la Nueva España el trabajo

así como el linaje y la situación legal. NAVARRETE LINARES, Federico. Discriminación étnica y desigualdades en México: una reflexión histórica. In: CASTRO, Elisabetta di, (Ed.). La desigualdad en México: perspectivas interdisciplinarias. México: Universidad Nacional Autónoma de México, en prensa.

${ }^{6}$ MONTEIRO, John M. Negros da Terra. Índios e bandeirantes nas origens de São Paulo. São Paulo: Companhia das Letras, 1994, p. 154-155.

${ }^{7}$ Las colonias protestantes de América del Norte no tenían el mismo espíritu universalista y no buscaron integrar a los indígenas a sus comunidades político-religiosas, ORTEGA Y MEDINA, Juan Antonio. La evangelización puritana en Norteamérica. Delendi sunt Indi. México: Fondo de Cultura Económica, 1976.

${ }^{8}$ ZAVALA, Silvio. La encomienda indiana. México: Editorial Porrúa, 1973. 
forzoso comenzó a desaparecer desde mediados del siglo XVII, ${ }^{9}$ en la región maya y los Andes se mantuvo hasta el XIX. ${ }^{10}$

Las sociedades de agricultores aldeanos y, más aún de cazadores-recolectores, recibieron un trato diferente. En primer lugar someterlos políticamente resultó mucho más difícil, ya que no tenían una tradición de obediencia a autoridades estatales, y explotar su trabajo también, en vista de que no conocían formas de trabajo obligatorio. Desde la colonización española del Caribe a fines del siglo XIV y las incursiones a la costa norte de América del Sur, hasta las grandes bandeiras paulistas del XVII, el secuestro y esclavización forzosa de miembros de estos grupos fue una estrategia para lograr explotar su fuerza de trabajo, ${ }^{11}$ aunque en el imperio español la esclavitud indígena fue abolida rápidamente y no jugó un papel tan importante como en el portugués. En este último fue fundamental la distinción entre indios aliados, que vivían en aldeas bajo la tutela de los frailes, y que tenían libertad y propiedad sobre su tierra, además de que en teoría debían trabajar sólo libremente y con remuneración, y los indios bárbaros contra los que se podía hacer "guerra justa" y que podían ser esclavizados. ${ }^{12}$

Igualmente el despojo territorial tuvo un peso mayor que en la relación con las sociedades campesinas, y en casos como el norte de México y la montaña peruana las tierras que solían pertenecer a estos pueblos fueron ocupadas frecuentemente por colonos indígenas venidos, respectivamente, de Mesoamérica y los Andes. Finalmente, las misiones jesuitas, franciscanas y de otras órdenes fueron claves para lograr la "pacificación" o "aldeamiento" de estos pueblos y posibilitar la explotación de su fuerza de trabajo. El ejemplo más conocido y espectacular son las misiones jesuitas en el Paraguay, pero más allá de éste los

\footnotetext{
${ }^{9}$ LOCKHART, James. Los nahuas después de la conquista. Historia social y cultural de los indios del México central, del siglo XVI al XVIII. México: Fondo de Cultura Económica, 1999. El mismo autor ha planteado un modelo comparativo muy útil para explicar la evolución diferente del régimen colonial en estas tres regiones, LOCKHART, James. Three Experiences of Culture Contact: Nahua, Maya and Quechua. In: Of Things of the Indies. Essays Old and New in Early Latin American History. Stanford: Stanford University Press, 1999, p. 204-228.

${ }^{10}$ SPALDING, Karen. Huarochirí. An Andean Society under Inca and Spanish Rule. Stanford: Stanford University Press, 1984.

${ }^{11}$ MONTEIRO, John M. Negros da Terra. Índios e bandeirantes nas origens de São Paulo. São Paulo: Companhia das Letras, 1994.

${ }^{12}$ PERRONE-MOISÉS, Beatriz. Índios livres e índios escravos. Os princípios da legislação indigenista do periodo colonial (séculos XVI a XVIII). In: CUNHA, Manuela Carneiro da (org.) História dos índios no Brasil. São Paulo: Companhia das Letras, 1992, p. 115-132.
} 
misioneros fueron esenciales para la expansión de la frontera colonial en los imperios español y portugués. ${ }^{13}$

Más allá de los espacios colonizados y sometidos por las misiones, surgieron espacios muy complejos de interacción y enfrentamientos con pueblos no sometidos que jugaron un papel importante para la dinámica de los imperios ibéricos. ${ }^{14}$ En Brasil, los pueblos "aldeados" servían como aliados en las excursiones contra el "gentío bárbaro" y sus aldeas se usaban para asegurar la frontera contra los segundos. ${ }^{15}$

Aunque los pueblos que vivían más allá de estas fronteras no estaban directamente sometidos a los imperios coloniales, cada uno de los aspectos de su vida era afectada por su presencia. ${ }^{16}$ Igualmente, estas regiones de frontera en las sierras y desiertos de América del Norte, en las selvas tropicales de América del Centro y del Sur y en las vastas praderas del Cono Sur, servían también de refugio a individuos y pueblos que escapaban a la dominación colonial, como los mayas rebeldes de Yucatán y los jíbaros y otros pueblos amazónicos. También se convirtieron en un horizonte de expansión con un gran significado geopolítico y simbólico para los proyectos coloniales rivales de portugueses y españoles.

\footnotetext{
${ }^{13}$ Véanse al respecto, entre muchas otras obras, los estudios de Ignacio del Río sobre las misiones jesuitas en el norte de México, DEL RÍO, Ignacio. Conquista y aculturación de la California jesuítica 1697-1768. México: Universidad Nacional Autónoma de México-Instituto de Investigaciones Históricas, 1984, (Serie de Historia Novohispana, 32). Para la frontera amazónica de los Andes, ESPINOZA, Waldemar. Amazonía del Perú. Historia de la Gobernación y Comandancia General de Maynas. Lima: Fondo Editorial del Congreso del Perú-Banco Central de Reserva del Perú, 2007. Recientemente Cynthia Radding ha planteado un estudio comparativo entre el noroeste de la Nueva España y la provincia de Charcas en América del Sur, RADDING, Cynthia. Landscapes of Power and Identity. Comparative Histories in the Sonoran Desert and the Forests of Amazonia from Colony to Republic. Durham: Duke University Press, 2005.

${ }^{14}$ El más brillante estudio de la compleja dinámica de estos espacios de frontera, que muestra su continuidad desde tiempos prehispánicos hasta los periodos independientes se encuentra en SANTOS, Fernando. Etnohistoria de la Alta Amazonia, siglos XV-XVIII. Quito: Ediciones AbyaYala, [1992], (Colección 500 años, 46).

${ }^{15}$ PERRONE-MOISÉS, Beatriz. Índios livres e índios escravos. Os princípios da legislação indigenista do periodo colonial (séculos XVI a XVIII). In: CUNHA, Manuela Carneiro da (org.) História dos índios no Brasil. São Paulo: Companhia das Letras, 1992, p. 121.

${ }^{16}$ RADDING, Cynthia. Wandering Peoples. Colonialism, Ethnic Spaces, and Ecological Frontiers in Northwestern Mexico, 1700-1850. Durham: Duke University Press, 1997.
} 


\section{La autonomía ecológica}

La "autonomía ecológica" es la capacidad que una comunidad tiene de reproducirse físicamente utilizando sus propias formas de producción. Al acuñar este concepto, John Tutino enfatizó su importancia para determinar la capacidad que tienen las comunidades indígenas y campesinas para enfrentarse política y militarmente a los estados coloniales y nacionales. ${ }^{17}$ El concepto gana aún más poder explicativo si se extiende más allá de la concepción tradicional de producción económica, para abarcar todas las maneras en que una sociedad participa de lo que David Harvey ha llamado la "red de la vida", es decir, su ámbito socio-ecológico en constante evolución, que abarca tanto el entorno natural como su propia vida productiva, social, religiosa y cultural. ${ }^{18}$ Se puede afirmar, incluso, que las especificidades culturales y las identidades étnicas de los pueblos amerindios sólo resultan comprensibles si tomamos en cuenta esta compleja interrelación. ${ }^{19}$

A principios del siglo XIX, las sociedades amerindias gozaban de grados muy diferentes de autonomía ecológica. En un extremo, los pueblos nahuas del centro de México habían sufrido un proceso de despojo de sus tierras de cultivo y de pérdida de control sobre sus bosques y sus fuentes de agua que había reducido radicalmente su autonomía, forzándolos a trabajar en las haciendas circundantes para obtener dinero para adquirir en el mercado buena parte de sus alimentos. Esto había creado una relación simbiótica entre las comunidades indígenas y las grandes haciendas de los criollos y españoles que erosionaba lenta pero constantemente la autonomía ecológica de las primeras convirtiéndolas cada vez más en un semi-proletariado rural. ${ }^{20}$ No sorprende que estas comunidades asediadas hayan convertido la defensa de las tierras que les quedaban, y de sus

\footnotetext{
${ }^{17}$ TUTINO, John. The Revolutionary Capacity of Rural Communities: Ecological Autonomy and its Demise. In: TUTINO, John, SERVÍN, Elisa e REINA, Leticia (eds.) Cycles of Conflict, Centuries of Change: Crisis, Reform, and Revolution in Mexico. Durham: Duke University Press, 2007, p. 214.

${ }^{18}$ HARVEY, David. Notes towards a theory of uneven geographical development. In: Spaces of Global Capitalism: A Theory of Uneven Geographical Development. Londres: Verso, 2006, p. 46-47. ${ }^{19}$ Véanse al respecto las reflexiones de CASTRO, Eduardo Viveiros de. Perspectivismo e multinaturalismo na América indígena. In: A inconstância da alma selvagem. São Paulo: Cosac \& Naify, 2002, p. 345-200.

${ }^{20}$ TUTINO, John. Agrarian Social Change and Peasant Rebellion in Nineteenth Century Mexico: The Example of Chalco. In: KATZ, Friedrich (ed.). Riot, Rebellion and Revolution. Rural Social Conflict in Mexico. Princeton: Princeton University Press, 1988, p. 98-101.
} 
últimos márgenes de autonomía ecológica, en un elemento clave de la definición de sus identidades étnicas. ${ }^{21}$

Las comunidades del centro y sur de los Andes habían podido preservar su relación con la red de la vida en un grado mayor, pues los españoles no habían sentido la misma atracción por sus tierras y recursos en una región montañosa que les resultaba impenetrable. Sin embargo, dos factores habían debilitado seriamente la autonomía ecológica de los pueblos indígenas: el primero fue la desintegración de los complejos sistemas de intercambio que solían garantizarles acceso a los recursos provenientes de los distintos pisos ecológicos de la cordillera de los Andes, la región costera y la montaña amazónica y que eran claves para la viabilidad ecológica y económica de las comunidades $;{ }^{22}$ el segundo fue el impacto negativo que habían tenido sobre ellos las formas de explotación impuestas por el gobierno colonial, particularmente el trabajo forzoso en las minas por medio de la mita. Por ello, pese a su relativa autarquía, estas comunidades vivían en una situación de precariedad que atribuían directamente a los abusos de las autoridades coloniales. Como resultado, los españoles eran considerados vampiros y caníbales que devoraban la grasa y sangre de los indígenas, lo que explica en parte la violencia de las insurrecciones andinas del siglo XVIII. ${ }^{23}$

Los pueblos mayas de Guatemala y de Yucatán gozaban de una mayor autonomía ecológica, pues sus tierras no habían sido despojadas en gran escala por los escasos colonos españoles que vivían en sus regiones y su mano de obra tampoco era explotada de manera sistemática; además, pagaban sus tributos con los excedentes de los productos de su economía tradicional. Esto les permitía reproducir de manera más o menos estable e independiente sus relaciones con la red de la vida, aunque su autonomía respecto a los poderes coloniales era limitada por el hecho de que la religión católica había pasado a formar una parte central de la dimensión simbólica y ritual de esta relación. ${ }^{24}$

\footnotetext{
${ }^{21}$ KATZ, Friedrich. Rural Uprisings in Preconquest and Colonial Mexico. In: KATZ, Friedrich (ed.). Riot, Rebellion and Revolution. Rural Social Conflict in Mexico. Princeton: Princeton University Press, 1988, p. 67-94.

${ }^{22}$ MURRA, John V. Formaciones económicas y políticas del mundo andino. Lima: Instituto de Estudios Peruanos, 1975.

${ }^{23}$ SZEMINSKI, Jan. ¿Por qué matar a los españoles? Nuevas perspectivas sobre la ideología andina... In: STERN, Steve J. (ed.). Resistencia, rebelión y conciencia campesina en los Andes. Lima: Instituto de Estudios Peruanos, 1987, p. 164-186.

${ }^{24}$ FARRISS, Nancy M. La sociedad maya bajo el dominio colonial. La empresa colectiva de la supervivencia. Madri: Alianza Editorial, 1992. CARMACK, Robert M. The Quiché Mayas of Utatlan. The Evolution of a Highland Guatemala Kingdom. Norman: University of Oklahoma Press, 1981.
} 
No obstante, los pueblos mayas de la selva tropical del Petén y de Yucatán pudieron aprovechar su autonomía ecológica y la relativa inaccesibilidad de esta región para los españoles para escapar de la dominación colonial y construir comunidades libres. $^{25}$

Las selvas tropicales de América Central y del Sur ofrecían las mismas posibilidades de autonomía ecológica y refugio a los pueblos de agricultores aldeanos que se enfrentaron al avance de los colonos y bandeirantes españoles y lusitanos. A la fecha, la manera en que sociedades amazónicas como los jíbaros, o shuar, se relacionan con la red de la vida puede explicarse en función de su evasión del dominio colonial. ${ }^{26}$ Para contrarrestar esta libertad de los pueblos indígenas selváticos, basada en su autonomía ecológica, los colonizadores tuvieron que establecer y mantener monopolios sobre bienes escasos, como la sal o las herramientas de metal, y así someterlos a relaciones de dependencia. ${ }^{27}$ Significativamente, las tradiciones de esos pueblos contienen abundantes relatos míticos para explicar la capacidad de los europeos de controlar estos bienes materiales escasos y atractivos, que suelen atribuir a un error de los indígenas que no supieron aprovecharlos. ${ }^{28}$

Los pueblos de cazadores y recolectores, o de agricultores aldeanos, que habitaban las planicies, desiertos y bosques templados de América del Norte y del Sur también gozaban de un alto grado de autonomía ecológica, aunque su relación con la red de la vida había sido afectada en mayor medida por la presencia europea. Los mapuches o araucanos, los tehuelches y los pueblos del Chaco en el Cono Sur, así como los comanches y otros grupos de las praderas de América del Norte, se beneficiaron por la adopción del caballo venido de Europa, que les permitió potenciar su economía cazadora, conquistar a otros pueblos indígenas y defenderse con eficacia frente al avance del imperio español

\footnotetext{
${ }^{25}$ CASO BARRERA, Laura. Caminos en la selva. Migración, comercio y resistencia. Mayas yucatecos e itzaes, siglos XVII-XIX. México: Fondo de Cultura Económica-El Colegio de México, 2002 e JONES, Grant D. The Conquest of the Last Maya Kingdom. Stanford: Stanford University Press, 1998.

${ }^{26}$ DESCOLA, Philippe. Homeostasis as a Cultural System: The Jivaro Case. In: ROOSEVELT, Anna (ed.). Amazonian Indians from Prehistory to the Present. Tucson: The University of Arizona Press, 1994, p. 203-224.

${ }^{27}$ BROWN, Michael F. e FERNÁNDEZ, Eduardo. War of Shadows. The Struggle for Utopia in the Peruvian Amazon. Berkeley: University of California Press, 1991.

${ }^{28}$ Los ejemplos son muchos, entre ellos, VARESE, Stéfano. Pachacamaite. In: OSSIO A., Juan M. (ed.). Ideología mesiánica del mundo andino. Lima: s.n., 1973, p. 359-374.
} 
en sus territorios. ${ }^{29}$ Sin embargo, con el creciente acceso a las armas de fuego en el siglo XIX terminarían por romper el delicado equilibrio con las especies que cazaban y por destruir así las bases de su autonomía ecológica, ayudados un proceso acelerado por la participación activa de los colonos europeos. ${ }^{30}$

En contraste, los pueblos que fueron incorporados a las misiones católicas experimentaron una radical transformación de su relación con la red de la vida. Como parte de su programa de evangelización y dominación política, los misioneros les impusieron la práctica de la agricultura y de la ganadería, así como el trabajo en minas u otras factorías a la manera europea. La vida de las misiones estuvo marcada por la dificultad que tuvieron estos pueblos por cambiar tan radicalmente sus antiguas prácticas productivas, que estaban íntimamente relacionadas con su identidad y sus valores. Por ello muchos de estos grupos huyeron del control misionero. ${ }^{31}$ En los casos en que esta transformación fue exitosa, significó la disolución irreversible de las antiguas relaciones de estos pueblos con la red de la vida y los colocó en una situación de total dependencia hacia los misioneros y la economía colonial, lo que provocó su extinción cuando estas misiones fueron abandonadas, por la expulsión de los jesuitas o por otras causas. ${ }^{32}$

\section{El control cultural}

El "control cultural" es la capacidad que tiene un grupo o sociedad para dirigir la transformación de su propia cultura, asimilando elementos culturales ajenos o conservando los suyos propios, de acuerdo a sus necesidades sociales y objetivos políticos en un momento histórico determinado. Este concepto, propuesto originalmente por Guillermo Bonfil, ${ }^{33}$ permite comprender las transformaciones culturales y sociales de los pueblos indígenas en el contexto colonial

\footnotetext{
${ }^{29}$ MARTÍNEZ SARASOLA, Carlos. Nuestros paisanos los indios. Vida, historia y destino de las comunidades indigenas argentinas. Buenos Aires: Emecé, 1992.

${ }^{30}$ ISENBERG, Andrew C. The destruction of the Bison: An Environmental History, 1750-1920. Cambridge: Cambridge University Press, 2000.

${ }^{31}$ Estos complejos procesos son analizados con detalle para el caso de las misiones jesuitas entre los guaraníes in ARMANI, Alberto. Ciudad de Dios y Ciudad del Sol. México: Fondo de Cultura Económica, 1982.

${ }^{32}$ DEL RÍO, Ignacio. Conquista y aculturación de la California jesuítica 1697-1768. México: Universidad Nacional Autónoma de México-Instituto de Investigaciones Históricas, 1984.

${ }^{33}$ BONFIL BATALLA, Guillermo. El etnodesarrollo: sus premisas jurídicas. Políticas y organización. In: Obras escogidas de Guillermo Bonfil. México: Instituto Nacional Indigenista-Instituto Nacional de Antropología e Historia, 1995, vol. 2, p. 467-480.
} 
más allá de la dicotomía simplista entre una ininterrumpida continuidad cultural con los tiempos prehispánicos y una radical aculturación que implicaría que fueron occidentalizados irreversiblemente. Sin embargo, para que este concepto permita realmente profundizar nuestra comprensión, es necesario cuestionar la unidad misma de las sociedades indígenas y plantear los siguientes interrogantes: ¿quién ejerce en mayor medida el control cultural en su interior, las élites o los grupos subordinados?; ¿cuál es la relación entre la cultura de estos estratos y como se construyen consensos entre ellos?; ¿cómo se definen las identidades culturales hacia adentro y hacia afuera del grupo?

Sólo de esta manera podremos comprender las situaciones que se podrían calificar de paradójicas entre los pueblos de Mesoamérica y los Andes. A primera vista, los grupos del centro de México parecerían gozar de un grado reducido de control cultural, pues sus élites tradicionales habían desaparecido desde principios del siglo XVII y sus sociedades habían experimentado un proceso de campesinización y atomización. ${ }^{34}$ Igualmente, su cultura había sido profundamente cristianizada de modo que la figura del Santo Patrono católico, convertido en el símbolo de la comunidad y en el principal defensor de sus tierras, y de los rituales vinculados a él, se había convertido en el centro de una identidad cultural que estaba claramente subordinada al dominio español, pues atribuía a las autoridades coloniales un papel central en la fundación y continuidad de los pueblos indígenas. ${ }^{35}$ Sin embargo, a lo largo de la segunda mitad del periodo colonial estas comunidades y sus identidades fueron capaces de adaptarse y resistir al embate de las haciendas, la creciente incorporación de sus miembros a los mercados laborales controlados por criollos y españoles, y las reformas borbónicas. Su efectividad se puede atribuir al alto grado de consenso de que gozaban estas identidades dentro de las propias comunidades y al hecho de que reutilizaban elementos claves de la ideología hegemónica española y por

\footnotetext{
${ }^{34}$ LOCKHART, James. Los nahuas después de la conquista. Historia social y cultural de los indios del México central, del siglo XVI al XVIII. México: Fondo de Cultura Económica, 1999.

${ }^{35}$ Esta identidad cultural es reflejada de manera muy clara en los Títulos primordiales escritos por algunas de estas comunidades en la segunda mitad del periodo colonial, véase LÓPEZ CABALLERO, Paula (ed.). Los Títulos Primordiales del Centro de México. México: Consejo Nacional para la Cultura y las Artes, 2003. Igualmente, NAVARRETE LINARES, Federico. El culto a los santos patronos y la resistencia comunitaria: la compleja relación entre la cristiandad y la búsqueda de identidades indígenas en el México colonial. In: MONDRAGÓN, Carlos (ed.). El cristianismo en perspectiva global: Impacto y presencia en Asia, Oceanía y las Américas. México: El Colegio de México, en prensa.
} 
lo tanto abrían a las comunidades un amplio margen de negociación con los poderes coloniales. Un ejemplo de esta fuerza paradójica es que ya desde el siglo XVIII hubo comunidades en esta región que abandonaron la lengua náhuatl y adoptaron el español sin por ello perder o debilitar su identidad étnica. ${ }^{36}$ Por más acotado que nos parezca, este margen de control cultural permitiría a los pueblos del centro de México participar activamente en los sucesos políticos desencadenados en 1808.

A primera vista, los pueblos andinos parecerían gozar de un mayor grado de control cultural, pero en la práctica sus contradicciones internas lo limitaban trágicamente. Desde el siglo XVI, las élites indígenas habían mantenido y aumentado su situación de privilegio y poder, convirtiéndose en mediadores claves para la administración colonial. ${ }^{37}$ Estos grupos dirigentes fueron capaces de asimilar elementos claves de la ideología política y la cultura hispanas para construir una fuerte identidad aristocrática, centrada en su relación de descendencia con los Incas prehispánicos y, también, en su cristianismo, que los definía como colaboradores privilegiados de la dominación española. ${ }^{38}$

Simultáneamente, los campesinos indígenas construyeron una identidad étnica centrada también en la figura del Inca prehispánico, convertido en el Inkarrí, un antiguo gobernante con poderes sobrenaturales que había presidido sobre un régimen de justicia y abundancia antes de ser decapitado por los españoles y que habría de resucitar para terminar con el régimen colonial español y sus abusos en un cataclismo cósmico equivalente al que había provocado la conquista española. Al igual que la identidad aristocrática, esta construcción popular, incorporaba elementos claves del catolicismo, entre ellos la expectativa milenarista, pero a diferencia de ella tenía un carácter marcadamente anti-español y anti-colonial. Las contradicciones entre estos grupos se hicieron evidentes en la gran rebelión de Túpac Amaru y Túpac Katari en 1781, cuando las demandas

\footnotetext{
${ }^{36}$ LOCKHART, James. Los nahuas después de la conquista. Historia social y cultural de los indios del México central, del siglo XVI al XVIII. México: Fondo de Cultura Económica, 1999, p. 460-463.

${ }^{37}$ STERN, Steve J. Los pueblos indígenas del Perú y el desafio de la conquista española. Madrid: Alianza Editorial, 1982.

${ }^{38}$ Esta construcción identitaria se manifestó de manera singularmente rica en las artes visuales, particularmente en las pinturas de la escuela "cuzqueña", MAJLUF, Natalia (et. al.). Los incas, reyes del Perú. Lima: Banco de Crédito, 2005.
} 
y la violencia de las masas campesinas rebasaron a las élites y las orillaron a apoyar a la represión española. ${ }^{39}$

Tras la rebelión, el gobierno colonial reprimió y desarticuló a las élites indígenas y para principios del siglo XIX había logrado casi terminar con sus privilegios y con su capacidad de control cultural. Las comunidades campesinas, por su parte, fueron sometidas a un nuevo régimen de dominio señorial, a cargo de funcionarios españoles y de potentados no-indígenas, que no hizo más que profundizar su rechazo a la dominación española y la construcción de una identidad cultural campesina y nativista, centrada todavía en la figura del Inkarrí. ${ }^{40}$

Las comunidades mayas gozaban de un margen amplio de control cultural que era ejercido, fundamentalmente, por sus propias élites. En las tierras altas de Guatemala existía una clara continuidad entre los linajes gobernantes de las comunidades desde el siglo XVI, y éstos habían construido una poderosa identidad cultural altamente corporativa y centrada en una interpretación propia de la religión católica, conocida como el costumbre hasta la fecha. ${ }^{41}$ Por otro lado, los grupos subordinados dentro de las comunidades defendían una identidad cultural nativista que se complementaba con la que proponían las elites, aunque también llegaba a enfrentarse a ella. ${ }^{42}$ Esta doble dinámica permitió que elementos culturales impuestos por el poder colonial, como el catolicismo, y

\footnotetext{
${ }^{39}$ STERN, Steve. J. La era de la insurrección andina, 1742-1782: una reinterpretación. In: STERN, Steve J (ed.). Resistencia, rebelión y conciencia campesina en los Andes. Lima: Instituto de Estudios Peruanos, 1987, p. 50-96.

${ }^{40} \mathrm{La}$ continuidad de esta figura y su importancia para las comunidades indígena andinas es objeto de controversia entre los especialistas. Los descubridores de las tradiciones del Inkarrí en la década de 1970 propusieron su vigencia ininterrumpida desde el periodo colonial, ARGUEDAS, José María e ROEL PINEDA, Josafat. Tres versiones del mito del Inkarrí. In: OSSIO A., Juan M. (ed.). Ideología mesiánica del mundo andino. Lima: 1973, p. 219-225. Esta es la hipótesis que desarrollaron Flores Galindo y Manuel Burga al proponer el concepto de "utopía andina", FLORES GALINDO, Alberto. Buscando un Inca. Identidad y utopía en los Andes. México: Grijalbo/Consejo Nacional para la Cultura y las Artes, 1993 e BURGA, Manuel. Nacimiento de una utopía. Muerte y resurrección de los Incas. Lima: Universidad Mayor de San Marcos-Universidad de Guadalajara, 2005. Más recientemente otros especialistas han cuestionado esta continuidad, véase, por ejemplo, ESTENSSORO, Juan Carlos. Del paganismo a la santidad: la incorporación de los indios del Perú al catolicismo, 1532-1750. Lima: Instituto Frances de Estudios AndinosPontificia Universidad Católica del Perú, 2003.

${ }^{41}$ TEDLOCK, Barbara. Time and the Highland Maya. Albuquerque: University of New Mexico Press, 1992.

${ }^{42}$ CARMACK, Robert M. State and community in Nineteenth-Century Guatemala: The Momostenango Case. In: SMITH, Carol A. (ed.).Guatemalan Indians and the State: 1540 to 1988. Austin: University of Texas Press, 1990, p. 129-130.
} 
los trajes diferenciados para cada comunidad, fueran transformados en puntos claves de la identidad étnica indígena.

En Yucatán, las élites tradicionales vieron desaparecer muchos de sus privilegios económicos y políticos, pero lograron mantener su hegemonía cultural, gracias al control que tenían sobre la tradición histórica maya, basada en una concepción cíclica del tiempo, conocida como la "rueda de los katunes", que adaptaron de manera altamente creativa a la situación colonial, al interpretar retrospectivamente la conquista española para poder profetizar su eventual terminación, y también al incorporar el catolicismo dentro de este esquema temporal. ${ }^{43}$ Estos elementos se convirtieron en la base de una fuerte identidad cultural compartida por las sociedades mayas en toda la región que se centraba en un rechazo de la dominación española, y en la esperanza y el proyecto histórico de su eventual terminación y de la construcción de un nuevo cristianismo bajo el control de los propios mayas. ${ }^{44}$

En las sociedades de campesinos aldeanos y cazadores recolectores el control cultural era mucho más disperso y era ejercido, de manera temporal, por figuras carismáticas como los chamanes y los jefes de guerra. ${ }^{45}$ Muchas veces eran ellos quienes negociaban pactos con los misioneros o colonos españoles y su capacidad de liderazgo determinaba el mayor o menor éxito de la adaptación del grupo a los cambios culturales resultantes de la nueva situación. Sin embargo, estos procesos podían interrumpirse abruptamente al declinar la autoridad de estas figuras, provocando cambios radicales en la actitud de los grupos incorporados a las misiones. ${ }^{46}$ En otras ocasiones, estos dirigentes encabezaban la oposición a las iniciativas colonizadoras y llegaron a liderar

\footnotetext{
${ }^{43}$ Sobre la concepción cíclica de la historia centrada en la rueda de los katunes véase EDMONSON, Munro S. (ed.). The Ancient Future of the Itza. The Book of Chilam Balam of Tizimin. Austin: University of Texas Press, 1982. Sobre el cristianismo maya colonial, REIFLER-BRICKER, Victoria. El Cristo indígena, el Rey nativo. México: Fondo de Cultura Económica, 1993.

${ }^{44}$ FARRISS, Nancy. Recordando el futuro, anticipando el pasado: tiempo histórico y tiempo cósmico entre los mayas de Yucatán. In: La memoria y el olvido. Segundo Simposio de Historia de las Mentalidades. México: Instituto Nacional de Antropología e Historia, 1985, p. 47-60.

${ }^{45}$ MIRAFUENTES, José Luis. Agustín Ascuhul, el profeta de Moctezuma. Milenarismo y aculturación en Sonora (Guaymas, 1737). In: Estudios de Historia Novohispana, 1992, v.. 12, no 12, p.123-142.

${ }^{46}$ Véase la muy interesante discusión de este tema en CASTRO, Eduardo Viveiros de. O mármore e a murta: sobre a inconstância da alma selvagem. In: A inconstância da alma selvagem. São Paulo: Cosac \& Naify, 2002, p. 181-264.
} 
movimientos de "revitalización" con un fuerte contenido anti-colonial. ${ }^{47}$ Estos movimientos son muy complejos y diversos pero la mayoría, aun los que se definían explícitamente como "nativistas" incorporaron elementos cristianos y occidentales y a partir de ellos contribuyeron a la definición de nuevas identidades culturales que permitieron que los pueblos indígenas se adaptaran a las condiciones, a veces radicalmente diferentes, de la dominación colonial o que lograran escapar de ella. ${ }^{48}$

Un ejemplo de la capacidad de control cultural que podían ejercer estos grupos fue la manera en que los yaquis y huicholes del norte de México refuncionalizaron las creencias e instituciones que les habían impuesto las misiones jesuitas y las convirtieron en elementos claves de una nueva identidad orgullosamente independiente cuando éstas fueron abandonadas por la expulsión de la orden. ${ }^{49}$ En contraste, los bororo del Mato Grosso han sido capaces de mantener sus complejos rituales funerarios, vinculados de manera íntima con la red de la vida y su identidad cultural, pese a que han estado sometidos al régimen misionero desde mediados del siglo XVIII. ${ }^{50}$

\section{La capacidad de etnogénesis y la respuesta a la crisis de 1808}

El concepto de etnogénesis ha sido aplicado por diversos antropólogos americanistas para explicar la manera en que los grupos indígenas fueron capaces de recrear sus culturas y sus identidades étnicas para adaptarse a las complejas realidades de la colonización española. ${ }^{51}$ Este concepto enfatiza el carácter

\footnotetext{
${ }^{47}$ BROWN, Michael F. Beyond Resistance: A Comparative Study of Utopian Renewal in Amazonia. In: Ethnohistory, v. 38, 1991, n. 4, p. 388-413.

${ }^{48}$ NAVARRETE LINARES, Federico. La Tierra sin Mal, una utopía anti-estatal americana. In: OLIVIER, Guilhem (coord.). Símbolos de poder en Mesoamérica, México: Universidad Nacional Autónoma de México-Instituto de Investigaciones Históricas-Instituto de Investigaciones Antropológicas, en prensa.

${ }^{49}$ Sobre los primeros véase SPICER, Edward H. Los yaquis. Historia de una cultura. México: Universidad Nacional Autónoma de México-Instituto de Investigaciones Históricas, 1994; sobre los segundos, NEURATH, Johannes. Las fiestas de la Casa Grande. México: Instituto Nacional de Antropología e Historia-Universidad de Guadalajara, 2002.

${ }^{50}$ VIERTLER, Renate Brigitte. A refeição das almas: uma interpretação etnológica do funeral dos índios bororo -Mato Grosso. São Paulo: HUCITEC, 1991.

${ }^{51}$ Véase la formulación teórica de HILL, Johnathan D. Introduction. Ethnogenesis in the Americas, 1492-1992. In: HILL, Jonathan D. (ed.). History, Power and Identity: Ethnogenesis in the Americas, 1492-1992. Des Moines: University of Iowa Press, 1996, p. 1-2; también es interesante la de RADDING, Cynthia. Wandering Peoples. Colonialism, Ethnic Spaces, and Ecological Frontiers in Northwestern Mexico, 1700-1850. Durham: Duke University Press, 1997, p. 249-250.
} 
novedoso y creativo que tienen estas adaptaciones, y la agencia histórica de los propios indígenas en ellas y así permite comprender las transformaciones históricas de estas sociedades más allá de la contraposición simplista entre una resistencia, que debería ser hostil e impermeable a las influencias culturales y políticas occidentales, y un sometimiento y asimilación, que implicaría la disolución irreversible de las identidades étnicas y culturales indígenas. Podemos así analizar la capacidad de las diferentes sociedades indígenas para generar proyectos políticos propios que respondían a sus necesidades e intereses y que les permitieron defender y modificar creativamente sus identidades étnicas, y también su capacidad de construir alianzas con otros grupos sociales para impulsar estos proyectos étnicos y políticos.

Como habrá resultado evidente por las discusiones anteriores, la capacidad de etnogénesis de los diferentes grupos indígenas era función, en buena medida, de sus grados de autonomía ecológica y de control cultural. Tomando en cuenta estos tres factores se puede intentar explicar la manera en que estas sociedades se adaptaron y sobrevivieron a la crisis de 1808 .

Los grupos mayas, tanto de Guatemala como de Yucatán, destacan por su capacidad para generar proyectos autónomos y para defender sus identidades culturales y étnicas. Por ejemplo, las crisis políticas en España y en Guatemala desencadenaron una rebelión indígena en Totonicapán en 1820, un año antes del estallido de la rebelión de Independencia en ese país, que luchó en contra del reestablecimiento del pago de tributo por los indios, abolido temporalmente por la constitución de Cádiz. Aunque esta rebelión ha sido interpretada como un brote nativista que buscaba restaurar la monarquía maya, muestra más bien la capacidad que tenía ese grupo para involucrarse en los sucesos políticos contemporáneos y defender las implicaciones positivas que podían tener para ellos. ${ }^{52}$ A lo largo del siglo XIX, las élites indígenas de las Tierras Altas de ese país se enfrentaron a los proyectos políticos nacionales que les eran adversos y establecieron alianzas políticas con los grupos y gobiernos nacionales y locales que los ayudaron a defender su autonomía política, las tierras de sus comunidades, así como sus privilegios dentro de ellas.$^{53}$ En este proceso se mostraron perfectamente capaces de utilizar e interpretar a su favor las nuevas concepciones

\footnotetext{
${ }^{52}$ REIFLER-BRICKER, Victoria. El Cristo indigena, el Rey nativo. México: Fondo de Cultura Económica, 1993, p. 153-167.

${ }^{53}$ TARACENAARRIOLA, Arturo (et. al.). Etnicidad, estado y nación en Guatemala, 1808-1944. Guatemala: Centro de Investigaciones Regionales de Mesoamérica, 2002.
} 
liberales de ciudadanía y gobierno representativo. ${ }^{54}$ Sin embargo, la fuerza de las identidades étnicas indígenas y la continuidad y actualización de las formas de segregación y discriminación practicadas por criollos y ladinos significó la profundización de las distancias entre estos grupos.

Los pueblos mayas de Yucatán no participaron tan activamente en la guerra de Independencia, pero a partir de 1847 iniciaron una rebelión tan importante como la de 1781 en los Andes que condujo al establecimiento de un conjunto de sociedades independientes en toda la parte oriental y sur de la Península. Esta rebelión fue provocada de manera directa por la expansión de las haciendas sobre las tierras tradicionales de los pueblos mayas, y por los conflictos militares entre grupos liberales y conservadores en la región, pero fue también la culminación del proyecto de liberación de la dominación colonial y de fundación de un cristianismo plenamente maya que había sido gestado durante varios siglos por las élites indígenas de la región. Como tal, gozó de un amplio consenso entre los campesinos mayas de la región, y entre un número importante de mestizos y afroamericanos, y fue la base de la definición de una nueva identidad étnica, orgullosamente independiente, la de los mayas cristianos o cruzoob, seguidores de la Cruz Parlante, símbolo central del nuevo cristianismo maya. Estas sociedades lograron mantener su independencia hasta el siglo XX gracias también a que establecieron alianzas con los ingleses que estaban establecidos en Belice. ${ }^{55}$

En el centro de México las sociedades indígenas participaron en grandes números en las sucesivas revueltas contra el poder español a partir de 1810, lo que dio a éstas una base social de una amplitud sin equivalente en el resto del continente. Como en el caso de otros sectores sociales, esta participación fue impulsada originalmente por la defensa de la legitimidad del monarca español Fernando VII frente a la usurpación francesa, pero evolucionó a otro tipo de reivindicaciones entre las que destacaba la igualdad y la abolición de tributos y servicios especiales. ${ }^{56}$ En las filas de los ejércitos insurgentes de José María

\footnotetext{
${ }^{54}$ GRANDIN, Greg. The Blood of Guatemala. A History of Race and Nation. Durham: Duke University Press, 2000.

${ }^{55}$ La literatura sobre la mal llamada "guerra de castas" de Yucatán es muy amplia. Destacan los siguientes libros: REED, Nelson. La guerra de castas de Yucatán. México: Ediciones Era, 1981: REIFLER-BRICKER, Victoria. El Cristo indígena, el Rey nativo. México: Fondo de Cultura Económica, 1993, p. 171-234: BARTOLOMÉ, Miguel Alberto. La resistencia maya: relaciones interétnicas en el oriente de la Península de Yucatán. México: Instituto Nacional de Antropología e Historia, 1981. ${ }^{56}$ VAN YOUNG, Eric. The Other Rebellion. Popular Violence, Ideology, and the Mexican Struggle
} 
Morelos y de Vicente Guerrero las comunidades campesinas indígenas mostraron su disposición y capacidad para establecer alianzas con otros sectores sociales en pos de estos objetivos comunes. ${ }^{57}$

Tras la independencia participaron activamente en las disputas entre liberales y conservadores y construyeron lo que Florencia Mallon ha llamado un "liberalismo popular" que interpretaba los conceptos de ciudadanía, derechos y representación de manera favorable a la defensa de su identidad étnica y de sus intereses económicos, sobre todo de su propiedad territorial. ${ }^{58}$ En este proceso, los pueblos indígenas abandonaron la condición de "indios" y adoptaron la de ciudadanos y campesinos, interpretando estos conceptos políticos de acuerdo a su sentido de pertenencia comunitaria. Igualmente transformaron en muchos casos sus sistemas de gobierno coloniales en sistemas municipales republicanos, igualmente mediados por sus concepciones del poder y la legitimidad. ${ }^{59}$

La participación indígena en la vida política nacional y la capacidad de las comunidades para redefinir sus identidades étnicas fueron una de las bases del proceso de mestizaje social que se inició en el siglo XIX y que cambiaría la fisonomía étnica de México. ${ }^{60}$

En los Andes, los grupos indígenas participaron menos activamente en las rebeliones independentistas, o lo hicieron con menor capacidad de defender sus reivindicaciones particulares. ${ }^{61}$ Esto se debió, en buena medida, a la desarticulación política de estas sociedades tras la derrota de la rebelión de 1780, y a la desconfianza que sentían los criollos ante cualquier movilización indígena. Sólo en el Cuzco hubo una participación indígena importante en una rebelión encabezada por criollos. ${ }^{62}$ Posteriormente, el gobierno independiente

\footnotetext{
for Independence, 1810-1821. Stanford: Stanford University Press, 2001.

${ }^{57}$ GUARDINO, Peter F. Peasants, Politics and the Formation of Mexico's National State. Stanford: Stanford University Press, 1996.

${ }^{58}$ MALLON, Florencia. Campesino y nación: la construcción de México y Perú poscoloniales. México: Centro de Investigaciones y Estudios Superiores en Antropología Social, 2003. Véase también THOMSON, Guy P.C. Patriotism, Politics and Popular Liberalism in Nineteenth Century. Mexico: Juan Francisco Lucas and the Puebla Sierra. Wilmington: Scholarly Resources, 1998.

${ }^{59}$ GUARISCO CANSECO, Claudia. Los indios del Valle de México y la construcción de una nueva sociabilidad política, 1770-1835. Toluca: El Colegio Mexiquense, 2003.

${ }^{60}$ NAVARRETE LINARES, Federico. Las relaciones interétnicas en México. México: Universidad Nacional Autónoma de México, 2004.

${ }^{61}$ MANRIQUE, Nelson. Las sociedades americanas en el ámbito de la formación inicial de los proyectos nacionales como culminación de los procesos de continuidad y ruptura. In: Historia General de América Latina. Madrid: Editorial Trotta-UNESCO, 2003, v. 5, p. 352-353.

${ }^{62}$ Demélas, Marie-Danielle. Estado y actores colectivos. El caso de los Andes. In: Inventando
} 
peruano terminó por disolver a las ya debilitadas élites indígenas, aboliendo definitivamente los cargos que ocupaban, aunque el gobierno boliviano continuó reconociendo su existencia. ${ }^{63} \mathrm{El}$ resultado fue la campesinización de las sociedades andinas peruanas. Estas comunidades más homogéneas reforzaron su sentido de identidad étnica en contraposición con los mistis, como llamaban a los no-indígenas, y no buscaron participar activamente ni fueron incluidas en la vida política nacional al menos hasta la guerra con Chile. ${ }^{64}$

En resumen, a diferencia de lo que aconteció en el centro de México, la independencia de los países andinos no logró zanjar las distancias sociales, económicas e identitarias entre los indígenas y los otros sectores de las sociedades nacionales, ${ }^{65}$ pero los pueblos andinos no fueron capaces de impulsar proyectos de autonomía e independencia, como los de los mayas.

Las sociedades de campesinos aldeanos y cazadores y recolectores que vivían en las fronteras de los imperios español y portugués no jugaron un papel significativo en los procesos de independencia, pero se enfrentaron desde muy pronto a los nuevos-estados nación como el brasileño, que codiciaban ahora sus territorios, más que su mano de obra como lo habían hecho los imperios coloniales. ${ }^{66}$ En el caso de Argentina, por ejemplo, la frontera con los fieramente independientes tehuelches se encontraba en el río Salado, a menos de 100 kilómetros de Buenos Aires, por lo que desde antes de la consumación de la independencia se formularon los primeros planes de expansión. ${ }^{67}$ A lo largo del siglo XIX, los pueblos indígenas libres serían objeto de violentas y sistemáticas campañas militares de despojo territorial e incluso genocidio, como la Guerra del Desierto argentina, la guerra de la Araucania en Chile y las campañas militares para conquistar el interior brasileño y someter a los "indios bravos" del norte de

la nación. Iberoamérica. Siglo XIX. ANNINO, Antonio e GUERRA, François Xavier (coords.). México: Fondo de Cultura Económica-Siglo XXI, 2003, p. 347-378.

${ }^{63}$ MANRIQUE, Nelson. Las sociedades americanas en el ámbito de la formación inicial de los proyectos nacionales como culminación de los procesos de continuidad y ruptura. In: Historia General de América Latina. Madrid: Editorial Trotta-UNESCO, 2003, v. 5, p. 359-360.

${ }^{64}$ MALLON, Florencia. Campesino y nación: la construcción de México y Perú poscoloniales. México: Centro de Investigaciones y Estudios Superiores en Antropología Social, 2003.

${ }^{65}$ THURNER, Mark. From Two Republics to One Divided. Alabama: Duke University, 1997. ${ }^{66}$ CUNHA, Manuela Carneiro da. Política indigenista no século XIX. In: CUNHA, Manuela Carneiro da (org.).História dos índios no Brasil. São Paulo: Companhia das Letras, 1992, p. 133-154.

${ }^{67}$ MARTÍNEZ SARASOLA, Carlos. Nuestros paisanos los indios. Vida, historia y destino de las comunidades indígenas argentinas. Buenos Aires: Emecé, 1992, p. 160-163. 
México. ${ }^{68}$ Las sociedades indígenas respondieron a estas agresiones por medio de la resistencia militar, que fue exitosa en un primer momento, pero que fue vencida por la superioridad numérica de los ejércitos nacionales que enfrentaban y por la erosión de la autonomía ecológica de los indígenas.

El sometimiento militar significó el exterminio de muchas de estas sociedades, particularmente de las de cazadores y recolectores. Para los sobrevivientes marcó una crisis profunda, pues su relación con la red de la vida y, por ende, aspectos esenciales de su identidad cultural y étnica fueron modificados de manera irreversible. ${ }^{69}$ La salida fue, forzosamente, una redefinición de estas identidades a partir de sus nuevas relaciones con la red de la vida que se realizó por medio de movimientos de revitalización que no han terminado hasta nuestros días. ${ }^{70}$ Igualmente, la frontera entre estos pueblos y las sociedades nacionales sigue siendo en la actualidad un espacio de violencia y explotación, y también un ámbito de una gran fuerza simbólica. ${ }^{71}$

La vitalidad y pluralidad de las sociedades amerindias en América Latina es una realidad tan importante a principios del siglo XXI como lo era a principios del XIX. Por ello es fundamental reconocer y comprender la participación que estos grupos han tenido en la conformación de nuestros estados-nación y la manera en que han redefinido y reinventado sus identidades étnicas y culturales en estos doscientos años. Para lograrlo debemos dejar de concebirlos como grupos ajenos a nuestras naciones y reconocerlos como protagonistas de su historia, y de la nuestra.

\footnotetext{
${ }^{68}$ HERNÁNDEZ SILVA, Héctor Cuauhtémoc. Insurgencia y autonomía. Historia de los pueblos yaquis: 1821-1910. México: Centro de Investigaciones y Estudios Superiores en Antropología Social, 1996, (Historia de los pueblos indígenas de México).

${ }^{69}$ LEAR, Jonathan. Radical Hope: Ethics in the Face of Cultural Devastation. Cambridge: Harvard University Press, 2006.

${ }^{70}$ AGÜERO, Oscar Alfredo. El milenio en la amazonía. Mito-utopía tupí-cocama, o la subversión del orden simbólico. Quito: Ediciones Abya-Yala, 1994.

${ }^{71}$ Taussig ha analizado la compleja naturaleza de la violencia en estas regiones fronterizas, TAUSSIG, Michael. Shamanism, Colonialism and the Wild Man. A Study in Terror and Healing. Chicago: The University of Chicago Press, 1987.
} 


\section{BIBLIOGRAFIA}

AGÜERO, Oscar Alfredo. El milenio en la amazonía. Mito-utopía tupí-cocama, o la subversión del orden simbólico. Quito: Ediciones Abya-Yala, 1994.

ANDREWS, George Reid. Afro-Latin America 1800-2000. Nova York: Oxford University Press, 2004.

ARGUEDAS, José María e Roel Pineda, Josafat. Tres versiones del mito del Inkarrí. In: OSSIO, A Juan M. (ed.). Ideología mesiánica del mundo andino. Lima: 1973, p. 219-225.

ARMANI, Alberto. Ciudad de Dios y Ciudad del Sol. México: Fondo de Cultura Económica, 1982

BARTOLOMÉ, Miguel Alberto. La resistencia maya: relaciones interétnicas en el oriente de la Península de Yucatán. México: Instituto Nacional de Antropología e Historia, 1981.

BONFIL BATALLA, Guillermo. El concepto de indio en América: una categoría de la situación colonial. In: Obras escogidas de Guillermo Bonfil. México: Instituto Nacional Indigenista-Instituto Nacional de Antropología e Historia, 1995, v. 1, p. 337-345.

BONFIL BATALLA, Guillermo. El etnodesarrollo: sus premisas jurídicas. Políticas y organización. In: Obras escogidas de Guillermo Bonfil. México, Instituto Nacional Indigenista-Instituto Nacional de Antropología e Historia, 1995, v. 2, p. 467-480.

BROWN, Michael F. Beyond Resistance: A Comparative Study of Utopian Renewal in Amazonia. In: Ethnohistory, v. 38, 1991, n. 4, p. 388-413.

BROWN, Michael F. y FERNÁNDEZ, Eduardo. War of Shadows. The Struggle for Utopia in the Peruvian Amazon. Berkeley: University of California Press, 1991.

BURGA, Manuel. Nacimiento de una utopía. Muerte y resurrección de los Incas. Lima: Universidad Mayor de San Marcos-Universidad de Guadalajara, 2005.

CARMACK, Robert M. State and community in Nineteenth-Century Guatemala: The Momostenango Case. In: SMITH, Carol A. (ed.).Guatemalan Indians and the State: 1540 to 1988. Austin: University of Texas Press, 1990, p. 129-130.

CARMACK, Robert M. The Quiché Mayas of Utatlan. The Evolution of a Highland Guatemala Kingdom. Norman: University of Oklahoma Press, 1981.

CASO BARRERA, Laura. Caminos en la selva. Migración, comercio y resistencia. Mayas yucatecos e itzaes, siglos XVII-XIX. México: Fondo de Cultura Económica-El Colegio de México, 2002.

CASTRO, Eduardo Viveiros de. O mármore e a murta: sobre a inconstância da alma selvagem. In: A inconstância da alma selvagem. São Paulo: Cosac \& Naify, 2002, p. 181-264.

CASTRO, Eduardo Viveiros de. Perspectivismo emultinaturalismonaAmérica indígena. In: A inconstância da alma selvagem. São Paulo: Cosac \& Naify, 2002, p. 345-200. 
CUNHA, Manuela Carneiro da. Política indigenista no século XIX. In: CUNHA, Manuela Carneiro da (org.). História dos índios no Brasil. São Paulo: Companhia das Letras, 1992, p. 133-154.

DEL RÍO, Ignacio. Conquista y aculturación de la California jesuítica 1697-1768. México: Universidad Nacional Autónoma de México-Instituto de Investigaciones Históricas, 1984, (Serie de Historia Novohispana, 32).

DEMÉLAS, Marie-Danielle. Estado y actores colectivos. El caso de los Andes. In: ANNINO, Antonio e GUERRA, François Xavier (coords.). Inventando la nación. Iberoamérica. Siglo XIX. México: Fondo de Cultura Económica-Siglo XXI, 2003, p. 347-378

DESCOLA, Philippe. Homeostasis as a Cultural System: The Jivaro Case. In: ROOSEVELT, Anna (ed.) Amazonian Indians from Prehistory to the Present. Tucson: The University of Arizona Press, 1994, p. 203-224.

EDMONSON, Munro S. (ed.). The Ancient Future of the Itza. The Book of Chilam Balam of Tizimin. Austin: University of Texas Press, 1982.

ESPINOZA, Waldemar. Amazonía del Perú. Historia de la Gobernación y Comandancia General de Maynas. Lima: Fondo Editorial del Congreso del Perú-Banco Central de Reserva del Perú, 2007.

ESTENSSORO, Juan Carlos. Del paganismo a la santidad: la incorporación de los indios del Perú al catolicismo, 1532-1750. Lima: Instituto Frances de Estudios Andinos-Pontificia Universidad Católica del Perú, 2003.

FARRISS, Nancy M. La sociedad maya bajo el dominio colonial. La empresa colectiva de la supervivencia. Madrid: Alianza Editorial, 1992.

FARRISS, Nancy. Recordando el futuro, anticipando el pasado: tiempo histórico y tiempo cósmico entre los mayas de Yucatán. In: La memoria y el olvido. Segundo Simposio de Historia de las Mentalidades. México: Instituto Nacional de Antropología e Historia, 1985, p. 47-60.

FLORES GALINDO, Alberto. Buscando un Inca. Identidad y utopía en los Andes. México: Grijalbo-Consejo Nacional para la Cultura y las Artes, 1993.

GRANDIN, Greg. The Blood of Guatemala. A History of Race and Nation. Durham: Duke University Press, 2000.

GUARDINO, Peter F. Peasants, Politics and the Formation of Mexico's National State. Stanford: Stanford University Press, 1996.

GUARISCO CANSECO, Claudia. Los indios del Valle de México y la construcción de una nueva sociabilidad política, 1770-1835. Toluca: El Colegio Mexiquense, 2003.

HARVEY, David. Notes towards a theory of uneven geographical development. In: Spaces of Global Capitalism: A Theory of Uneven Geographical Development. Londres: Verso, 2006, p. 46-47

HERNÁNDEZ SILVA, Héctor Cuauhtémoc. Insurgencia y autonomía. Historia de los 
pueblos yaquis: 1821-1910. México: Centro de Investigaciones y Estudios Superiores en Antropología Social, 1996, (Historia de los pueblos indígenas de México).

HILL, Johnathan D. Introduction. Ethnogenesis in the Americas, 1492-1592. In: HILL, Jonathan D. (ed.). History, Power and Identity: Ethnogenesis in the Americas, 1492-1992.Des Moines: University of Iowa Press, 1996, p. 1-2.

ISENBERG, Andrew C. The destruction of the Bison: An Environmental History, 1750-1920. Cambridge: Cambridge University Press, 2000.

JONES, Grant D. The Conquest of the Last Maya Kingdom. Stanford: Stanford University Press, 1998.

KATZ, Friedrich. Rural Uprisings in Preconquest and Colonial Mexico. In: KATZ, Friedrich (ed.). Riot, Rebellion and Revolution. Rural Social Conflict in Mexico. Princeton: Princeton University Press, 1988, p. 67-94.

LEAR, Jonathan. Radical Hope: Ethics in the Face of Cultural Devastation. Cambridge: Harvard University Press, 2006.

LOCKHART, James. Three Experiences of Culture Contact: Nahua, Maya and Quechua. In: Of Things of the Indies. Essays Old and New in Early Latin American History. Stanford: Stanford University Press, 1999, p. 204-228.

LOCKHART, James. Los nahuas después de la conquista. Historia social y cultural de los indios del México central, del siglo XVI al XVIII. México: Fondo de Cultura Económica, 1999.

LÓPEZ CABALleRO, Paula (ed.). Los Títulos Primordiales del Centro de México. México: Consejo Nacional para la Cultura y las Artes, 2003.

MAJLUF, Natalia (et. al.). Los incas, reyes del Perú. Lima: Banco de Crédito, 2005.

MALLON, Florencia. Campesino y nación: la construcción de México y Perú poscoloniales. México: Centro de Investigaciones y Estudios Superiores en Antropología Social, 2003.

MANRIQUE, Nelson. Las sociedades americanas en el ámbito de la formación inicial de los proyectos nacionales como culminación de los procesos de continuidad y ruptura. In: Historia General de América Latina. Madrid: Editorial Trotta-UNESCO, 2003, v. 5, p. 352-353

MARTÍNEZ SARASOLA, Carlos. Nuestros paisanos los indios. Vida, historia y destino de las comunidades indigenas argentinas. Buenos Aires: Emecé, 1992.

MIRAFUENTES, José Luis. Agustín Ascuhul, el profeta de Moctezuma. Milenarismo y aculturación en Sonora (Guaymas, 1737). In: Estudios de Historia Novohispana, 1992, v. 12, no. 12, p.123-142

MONTEIRO, John M.. Negros da Terra. Índios e bandeirantes nas origens de São Paulo. São Paulo: Companhia das Letras, 1994, p. 154-155.

MURRA, John V. Formaciones económicas y políticas del mundo andino. Lima: Instituto de Estudios Peruanos, 1975 
NAVARRETE LINARES, Federico. Discriminación étnica y desigualdades en México: una reflexión histórica. In: CASTRO, Elisabetta di (ed.). La desigualdad en México: perspectivas interdisciplinarias. México: Universidad Nacional Autónoma de México, en prensa.

NAVARRETE LINARES, Federico. El culto a los santos patronos y la resistencia comunitaria: la compleja relación entre la cristiandad y la búsqueda de identidades indígenas en el México colonial. In: MONDRAGÓN, Carlos, (ed.). $E l$ cristianismo en perspectiva global: Impacto y presencia en Asia, Oceanía y las Américas. México: El Colegio de México, en prensa.

NAVARRETE LINARES, Federico. La Tierra sin Mal, una utopía anti-estatal americana. In: OLIVIER, Guilhem (coord.). Símbolos de poder en Mesoamérica. México: Universidad Nacional Autónoma de México-Instituto de Investigaciones Históricas-Instituto de Investigaciones Antropológicas, en prensa.

NAVARRETE LINARES, Federico. Las relaciones interétnicas en México. México: Universidad Nacional Autónoma de México, 2004.

NEURATH, Johannes. Las fiestas de la Casa Grande. México: Instituto Nacional de Antropología e Historia-Universidad de Guadalajara, 2002.

ORTEGA Y MEDINA, Juan Antonio. La evangelización puritana en Norteamérica. Delendi sunt Indi. México: Fondo de Cultura Económica, 1976.

PERRONE-MOISÉS, Beatriz. Índios livres e índios escravos. Os princípios da legislação indigenista do periodo colonial (séculos XVI a XVIII). In: CUNHA, Manuela Carneiro da (org.). História dos índios no Brasil. São Paulo: Companhia das Letras, 1992, p. 115-132.

RADDING, Cynthia. Landscapes of Power and Identity. Comparative Histories in the Sonoran Desert and the Forests of Amazonia from Colony to Republic. Durham: Duke University Press, 2005.

RADDING, Cynthia. Wandering Peoples. Colonialism, Ethnic Spaces, and Ecological Frontiers in Northwestern Mexico, 1700-1850. Durham: Duke University Press, 1997.

REED, Nelson. La guerra de castas de Yucatán. México: Ediciones Era, 1981.

REIFLER-BRICKER, Victoria. El Cristo indígena, el Rey nativo. México: Fondo de Cultura Económica, 1993.

SANTOS, Fernando. Etnohistoria de la Alta Amazonia, siglos XV-XVIII. Quito: Ediciones Abya-Yala, [1992], (Colección 500 años, 46)

SPALDING, Karen. Huarochirí. An Andean Society under Inca and Spanish Rule. Stanford: Stanford University Press, 1984.

SPICER, Edward H. Los yaquis. Historia de una cultura. México: Universidad Nacional Autónoma de México-Instituto de Investigaciones Históricas, 1994

STERN, Steve J. Los pueblos indígenas del Perú y el desafío de la conquista es- 
pañola. Madri: Alianza Editorial, 1982.

STERN, Steve. J. La era de la insurrección andina, 1742-1782: una reinterpretación. In: STERN, Steve J. (ed.). Resistencia, rebelión y conciencia campesina en los Andes. Lima: Instituto de Estudios Peruanos, 1987, p. 50-96.

SZEMINSKI, Jan. ¿Por qué matar a los españoles? Nuevas perspectivas sobre la ideología andina... In: STERN, Steve J. (ed.). Resistencia, rebelión y conciencia campesina en los Andes. Lima: Instituto de Estudios Peruanos, 1987, p. 164-186.

TARACENAARRIOLA,Arturo(et. al.).Etnicidad, estadoynaciónen Guatemala, 18081944. Guatemala: Centro de Investigaciones Regionales de Mesoamérica, 2002.

TAUSSIG, Michael. Shamanism, Colonialism and the Wild Man. A Study in Terror and Healing. Chicago: The University of Chicago Press, 1987.

TEDLOCK, Barbara. Time and the Highland Maya. Albuquerque: University of New Mexico Press, 1992.

THOMSON, Guy P.C. Patriotism, Politics and Popular Liberalism in Nineteenth Century Mexico: Juan Francisco Lucas and the Puebla Sierra. Wilmington: Scholarly Resources, 1998.

THURNER, Mark. From Two Republics to One Divided. Alabama: Duke University, 1997.

TUTINO, John. Agrarian Social Change and Peasant Rebellion in Nineteenth Century Mexico: The Example of Chalco. In: KATZ, Friedrich (ed.). Riot, Rebellion and Revolution. Rural Social Conflict in Mexico. Princeton: Princeton University Press, 1988, p. 98-101.

TUTINO, John. The Revolutionary Capacity of Rural Communities: Ecological Autonomy and its Demise. In: TUTINO, John, SERVÍN, Elisa e REINA, Leticia (eds.). Cycles of Conflict, Centuries of Change: Crisis, Reform, and Revolution in Mexico. Durham: Duke University Press, 2007, p. 214.

VAN YOUNG, Eric. The Other Rebellion. Popular Violence, Ideology, and the Mexican Struggle for Independence, 1810-1821. Stanford: Stanford University Press, 2001.

VARESE, Stéfano. Pachacamaite. In: Ideología mesiánica del mundo andino. Ossio A. Juan M. (ed.). Lima: s.n., 1973, p. 359-374.

VIERTLER, Renate Brigitte. A refeição das almas: uma interpretação etnológica do funeral dos índios bororo - Matto Grosso. São Paulo: HUCITEC, 1991.

ZAVALA, Silvio. La encomienda indiana. México: Editorial Porrúa, 1973.

Recebido: março/2008 - Aprovado: setembro/2008 